\title{
A BAYESIAN FRAMEWORK FOR AGE MODELING OF RADIOCARBON-DATED PEAT DEPOSITS: CASE STUDIES FROM THE NETHERLANDS
}

\author{
Maarten Blaauw ${ }^{1,2} \bullet$ Ronald Bakker $^{3} \bullet \mathrm{J}^{\text {Andrés Christen }}{ }^{1} \bullet$ Valerie A Hall ${ }^{4} \bullet$ \\ Johannes van der Plicht ${ }^{5}$
}

\begin{abstract}
Recently, Bayesian statistical software has been developed for age-depth modeling ("wiggle-match dating") of sequences of densely spaced radiocarbon dates from peat cores. The method is described in non-statistical terms, and is compared with an alternative method of chronological ordering of ${ }^{14} \mathrm{C}$ dates. Case studies include the dating of the start of agriculture in the northeastern part of the Netherlands, and of a possible Hekla-3 tephra layer in the same country. We discuss future enhancements in Bayesian age modeling.
\end{abstract}

\section{INTRODUCTION}

Plateaus and age reversals in radiocarbon calibration curves (e.g. IntCal04, Reimer et al. 2004) are known to cause problems for interpreting individual ${ }^{14} \mathrm{C}$ dates (e.g. Guilderson et al. 2005). However, these peculiar features of calibration curves can be used to obtain precise age-depth models from high-resolution sequences of ${ }^{14} \mathrm{C}$ dates (matching the shape of such sequences to the shape of the calibration curve; Pearson 1986; van Geel and Mook 1989). This wiggle-match dating (WMD) technique is being used intensively for precise dating of trees (Pearson 1986; Slusarenko et al. 2001; Hogg et al. 2003; Kuzmin et al. 2004; Norström et al. 2005; Friedrich et al. 2006), peat deposits (Clymo et al. 1990; Christen et al. 1995; Kilian et al. 1995, 2000; Oldfield et al. 1997; Speranza et al. 2000; Mauquoy et al. 2002, 2004; Bakker 2003a; Blaauw et al. 2003, 2004; Donders et al. 2004; Garnett and Stevenson 2004; Charman and Garnett 2005; ACCROTELM, http://www2.glos.ac.uk/ accrotelm/), and other archives (Gulliksen et al. 1998; van de Plassche et al. 2002, 2003).

Although WMD often results in more precise age models than using individually calibrated dates, calculation of precision or error ranges is not straightforward for WMD. In recent years, a number of investigations attempted to obtain confidence intervals for WMD age models. Pearson (1986), Christen (2003), and Bronk Ramsey et al. (2001) constructed methods to find confidence limits of ${ }^{14} \mathrm{C}$ wiggle-matched annual tree rings. Fitting such series with exactly known growth rates is not the subject of the present paper; rather, we focus on raised bog peat deposits. These have the added difficulty that their individual accumulation histories are not known and must therefore be estimated in order to obtain an age model. Cores from these deposits often demonstrate hiatuses and/or changes in the accumulation rate, necessitating fitting of subsets and thus leading to complicated age models.

Until recently, sequences of ${ }^{14} \mathrm{C}$ dates for organic deposits were divided manually and heuristically into subsets, and these were matched to the calibration curve assuming linear accumulation within the individual subset (e.g. Blaauw et al. 2003). Chosen models then had to be adapted manually to avoid chronological overlap between subsets ("leaps back in time"). This manual approach is lim-

\footnotetext{
'Centre for Mathematical Research (CIMAT), A.P. 402, 36000 Guanajuato, Mexico.

${ }^{2}$ Corresponding author. Email: drieteenmeeuw@ hotmail.com. Presently at Department of Earth Sciences, Uppsala University, Villavägen 16, SE-752 36 Uppsala, Sweden. Currently on leave at School of Geography, Archaeology and Palaeoecology, Queen's University, Belfast BT71NN, Northern Ireland.

${ }^{3}$ Heesterlaan 6, 9713 NW Groningen, the Netherlands.

${ }^{4}$ School of Geography, Archaeology and Palaeoecology, Queen's University, Belfast BT71NN, Northern Ireland.

${ }^{5}$ Centre for Isotope Research, University of Groningen, Nijenborgh 4, 9747 AG Groningen, the Netherlands. Also: Faculty of Archaeology, Leiden University, P.O. Box 9515, 2300 RA Leiden, the Netherlands.
} 
ited as only small numbers of possible subsets could be checked (whereas, to give an example, there are 210 ways to divide a sequence of 20 dates into 3 subsets, and an infinite number of ways to do this for the continuous variable "depth"). Outliers appear regularly in high-resolution data sets and systematic approaches to take these into account were lacking in WMD. Moreover, models that gave good fits of the dates to the calibration curve would sometimes have unrealistic underlying age models (very low or high accumulation rates, or very large hiatuses).

To tackle the above issues, Blaauw and Christen (2005) recently published software called Bpeat. Here, we explain the approach in non-statistical terms, using detailed case studies, and suggest future improvements.

\section{THE BPEAT FRAMEWORK}

Bpeat (Blaauw and Christen 2005) uses Bayesian statistics, which is a framework for explicitly considering prior knowledge/assumptions when interpreting new data. Our software uses the following prior assumptions, based on paleoecological knowledge about raised bog peat deposits: i) peat age increases with depth; ii) peat accumulates linearly for a certain period of time, after which a hiatus and/or a change in accumulation rate can occur (piecewise linear model; wiggle-match dating using sections); iii) section division levels could lie at any depth of a core; iv) likely accumulation rates are between 10 and $20 \mathrm{yr} / \mathrm{cm}$, but other accumulation rates are possible; v) there is a weak dependency of accumulation rates between sections (see later); vi) hiatuses (gaps in the archive) can occur, with short-lasting hiatuses being more likely than long-lasting ones; and vii) every ${ }^{14} \mathrm{C}$ date has a prior probability of being an outlier (outlying dates automatically obtain lower weights in the age models).

The above prior information is translated into specific distributions (Figure 1c-e). Instead of using the well-known normal distribution, for the accumulation rate and hiatus length priors we use gamma distributions. These are defined through 2 parameters, and have the advantage of always obtaining positive values (this is useful for avoiding negative accumulation rates or jumps back in time during hiatuses) as well as allowing for flexible shapes (through varying the values of the underlying parameters; e.g. compare Figures $1 \mathrm{c}-\mathrm{d}$ with Figure 1e). For the accumulation rate, the gamma prior is shaped using the parameters AlphaMean and AlphaStd (default 20 and 10, respectively), while for the hiatus length HiatusA and HiatusB (both default 0.0005) are defined. It is important to note that the values of the priors are not universally applicable. Different values for the priors should be checked through plotting the prior distributions, and possibly adapted for individual case studies.

Here, we introduce a degree of dependence of accumulation rate between different sections, since we believe every site is subject to specific factors that should limit possible accumulation rates (e.g. precipitation regime, season length). If a peat bog accumulates at a certain constant rate during one period, owing to these site-specific limiting factors, it could not have an entirely different accumulation rate in a different section and period. We approach this dependence through a gamma distribution (Figure 1e), which acts as a multiplication factor that controls how much accumulation rates can differ between the sections of a core. Values taken from this distribution vary to a lesser or greater extent around 1.0, with the size of this variation set by the single parameter epsilon. Using an estimated value for the "global" accumulation rate of a core (e.g. $10 \mathrm{yr} / \mathrm{cm})$, the accumulation rate for every individual section will be given by multiplying the global accumulation rate by a value from the dependence distribution (e.g. $10 \times 0.9 \mathrm{yr} / \mathrm{cm}$ ). Usually, we set the dependence of accumulation rate between sections to be very weak, e.g. epsilon $=5$, which allows multiplication factors to vary between about 0.2 and 2 . 

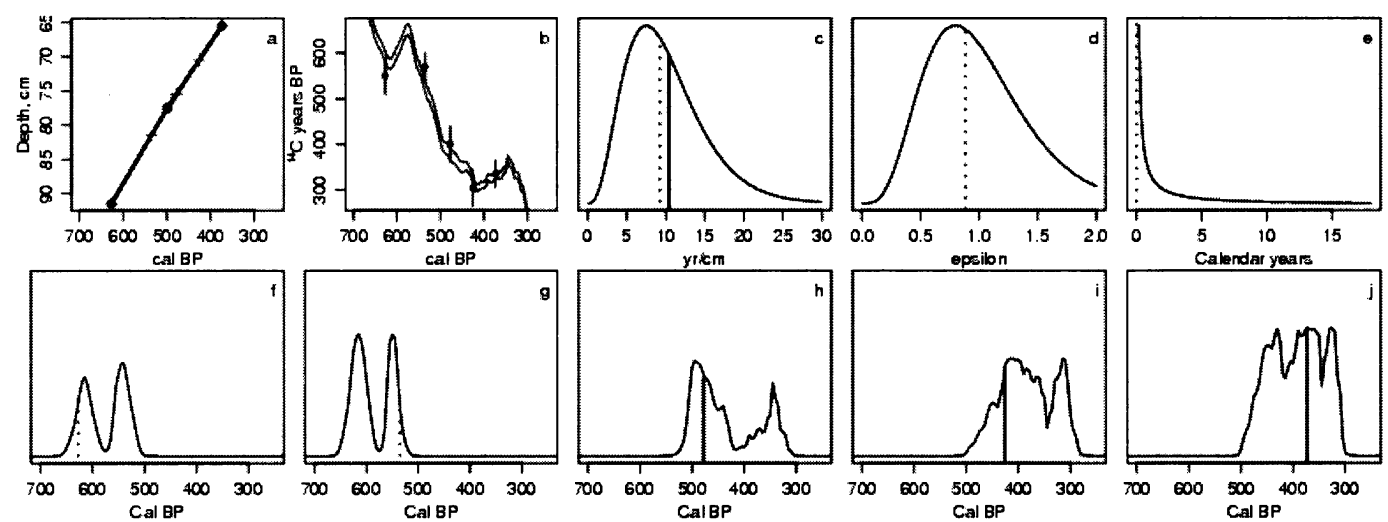

Figure 1 A simplified scheme of how Bpeat combines prior information with new data. Using a piecewise linear model with 2 sections, calendar ages are assigned to a simulated core with $5{ }^{14} \mathrm{C}$-dated levels $\left(\mathrm{a} ;{ }^{14} \mathrm{C}\right.$ dates sampled from Mauquoy et al. 2002), with a corresponding fit of the dates to the calibration curve (b). This particular model assumed a certain accumulation rate for every section (c), using a weak dependency of accumulation rates between sections (d), and a hiatus between the sections which most likely is small (e). The depicted age model assigns calendar ages to the 5 dated levels (f-j); its probability is the product of the heights of the probability distributions of the priors and the data (the vertical lines in [f-j]; continuous: upper section, dotted: lower section). A different age model would result in different values for the priors and in different assigned calendar ages for the dated levels, with as result a different product of probability densities. Not shown are the priors for outlying dates (standard 5\%), depths of section breaks, and initial start year (the last 2 have uniform priors); $y$ scales arbitrary unless indicated otherwise.

Outlying dates are handled as in previous applications of the Bayesian framework to ${ }^{14} \mathrm{C}$ age modeling (Christen 1994a,b, 2003; Buck et al. 2003); if a date needs to be shifted more than 2 standard deviations in order to bring it into context with the other dates and the applied model, then it is labelled as outlier. This method differs from the agreement index in OxCal where the overlap between prior and posterior distributions is measured (Bronk Ramsey, forthcoming). Many reasons are known for outliers to appear in ${ }^{14} \mathrm{C}$ studies (unremoved contamination from other layers, handling and processing, mislabeling, typing errors, etc.) as well as some still unexplained factors, but it is argued that up to $5 \%$ of all ${ }^{14} \mathrm{C}$ dates are outlying (Blaauw and Christen 2005; Blaauw et al. 2005). Although the standard approach in Bpeat is to give the same prior outlier probability to all dates, this prior can be adapted for individual dates (e.g. Wohlfarth et al. 2006, where ${ }^{14} \mathrm{C}$ dates stemming from corroded leaves were given higher prior outlier probabilities than those of "clean," less suspect material).

Additional dating information can be included in Bpeat, e.g. tephra layers of known calendar ages (Vorren et al. 2007). This can be done simply by not calibrating such date points (since they are already provided on the calendar scale) using a dummy 1:1 "calibration curve," while the ${ }^{14} \mathrm{C}$ dates in the sequence are calibrated using the usual calibration curve.

On the basis of the above assumptions, the values of many parameters need to be estimated. These include the start year of the sequence, the accumulation rate and hiatus length for every section, and the outlier probability for every date. Their values are estimated through tens to hundreds of millions of Markov Chain Monte Carlo (MCMC) iterations, where every iteration contains point estimates for all parameters involved, simulated from the corresponding posterior distribution given all ${ }^{14} \mathrm{C}$ determinations and the prior assumptions of the parameters described above. Similarly, for every iteration a depth can be translated into a calendar age using the parameter values at this particular iteration; a histogram of the predicted calendar ages using all MCMC iterations will thus estimate 
the calendar age distribution of this depth. Such histograms can be depicted as grayscales, with darker grayscales indicating more likely calendar ages. As in every MCMC analysis, it is essential always to check for replicability/robustness of the results through assessing multiple runs (both using similar and adapted values for the MCMC settings and for the priors for number of sections, accumulation rate, hiatus length, and outliers).

Bpeat can be downloaded from www.cimat.mx/ blaauwm/Bpeat-1.zip (Windows) or www.cimat.mx/ jac/software.html (Linux). Both versions come with a manual, use a command line approach, and need the open-source and free statistical software R (www.r-project.org) to be installed on the computer.

\section{CASE STUDIES}

Here, we report on 2 case studies where a precise estimate for the calendar age of certain events was obtained using the framework described above. The first study aims to estimate the date of onset of agriculture in a region of the Netherlands through ${ }^{14} \mathrm{C}$ age modeling of pollen horizons, and the second example aims to estimate the calendar age of a micro-tephra layer encountered in a midHolocene raised bog peat deposit from the same region.

\section{Gietsenveentje}

In the central and western parts of the Netherlands, agriculture is assumed to have been introduced by members of the Swifterbant culture (about 6900-5400 cal BP; Raemaekers 1999), whereas in Drenthe (northeastern Netherlands), previous studies indicate that farmers of the Funnel Beaker culture (about 5400-4750 cal BP; van Zeist 1959, 1967; Casparie and Groenman-van Waateringe 1980) started agriculture later, around $5300 \mathrm{cal} \mathrm{BP}$. The inferred later start in this region could be due to a lack of palynological data, because most sediments (Sphagnum bogs) have either been removed to be used as fuel or are located far from Neolithic settlements. The Gietsenveentje pingo scar lies close $(600 \mathrm{~m})$ to archaeological settlements in Drenthe, and contains mid-Holocene gyttja and peat. Its palynological record has recently been studied in detail from replicate cores (Bakker 2003a,b). The regional start of agriculture (Neolithic Occupation period, NOP) can be reconstructed palynologically from 3 high-resolution ${ }^{14} \mathrm{C}$-dated cores (Table 1 ; in the sections of interest, GietenVA has 10 , GietenV-B 9, and GietenV-D $8{ }^{14} \mathrm{C}$ dates). The cores were analyzed using $\mathrm{BCal}$ assuming chronological ordering (Buck et al. 1999), and using Bpeat under the following assumptions (see above; Blaauw and Christen 2005): accumulation rate can vary greatly between about $>0$ and 150 $\mathrm{yr} / \mathrm{cm}($ AlphaMean = 50 [GietenV-A: 60], AlphaStd = 40 [GietenV-A: 20], epsilon =2); and hiatus length is most likely very short, but could at times last millennia (Hiatus $A=0.3$, HiatusB $=0.0005$ ). After testing several options, the best fits were obtained by dividing core GietenV-A into 3 sections, and the other cores into 2 sections (similar to Bakker 2003a). The prior for ${ }^{14} \mathrm{C}$ dates being outlying was set at $5 \%$.

Table 1 Neolithic Occupation Phases 1 and 2 as inferred from 3 cores in Gietsenveentje (Bakker 2003a). NOP-1 is divided into 2 sub-events when the Ulmus decline is asynchronous with the appearance of Plantago lanceolata. Cal BP ages are $95 \%$ ranges from the Bpeat posterior distributions, rounded to the nearest decade.

\begin{tabular}{llll}
\hline & GietenV-A & GietenV-B & GietenV-D \\
\hline NOP-1 & 1a: $376.5 \mathrm{~cm}, 6280-5990 \mathrm{cal}$ BP & $262.5 \mathrm{~cm}, 6220-5940 \mathrm{cal} \mathrm{BP}$ & $222.5 \mathrm{~cm}, 6170-5740 \mathrm{cal} \mathrm{BP}$ \\
& 1b: $370.5 \mathrm{~cm}, 5480-5320 \mathrm{cal}$ BP & & \\
NOP-2 & $366.5 \mathrm{~cm}, 5440-5170 \mathrm{cal}$ BP & $222.5 \mathrm{~cm}, 5670-5450 \mathrm{cal} \mathrm{BP}$ & $205.5 \mathrm{~cm}, 5580-5340 \mathrm{cal} \mathrm{BP}$ \\
\hline
\end{tabular}


NOP-1 was registered in the Gieten cores as a combination of a very gradual decline of Ulmus, a maximum of Tilia and Quercus, an increase in non-arboreal pollen, Gramineae, Calluna vulgaris, and Rumex acetosa, and the appearance of Plantago lanceolata and Cerealia-type (Bakker 2003a). In core GietenV-A, this zone was divided into $1 \mathrm{a}$ (Ulmus decline) and $1 \mathrm{~b}$ (appearance $P$. lanceolata) as the Ulmus decline was asynchronous with the appearance of $P$. lanceolata. In cores GietenV-A (NOP-1a) and GietenV-D (NOP-1), the event was located at the bottom of the sequence of ${ }^{14} \mathrm{C}$ dates, (Figure 2) with the lowest dates being rather isolated (in depth as well as in calendar age; no overlapping posterior distributions of individually calibrated dates). This resulted in rather wide confidence intervals for NOP-1 for both cores (Figure 3); indeed, Bpeat and BCal 95\% posterior distributions were comparable to ranges obtained by calibrating the individual dates. In core GietenV-B, the depth of NOP-1 was encompassed by multiple dates, but also here the posterior distributions of Bpeat as well as BCal were rather wide. In all 3 cases, NOP-1 is dated at around 6000 cal BP, although with century-wide uncertainty levels. The inferred onset of agriculture in northeastern Netherlands is thus found to be some 7 centuries earlier than previously assumed (van Zeist 1959, 1967; Casparie and Groenman-van Waateringe 1980), and was thus introduced by members of the Swifterbant culture. NOP-2 was registered as a gradual decrease of Tilia, large amounts of Gramineae and $C$. vulgaris, and maxima of $P$. lanceolata, $R$. acetosa, and Cerealia-type. This event of increased human impact was dated around 5600-5300 cal BP (Table 1, Figure 3) and provides an age for the start of the Funnel Beaker culture (whose farmers practiced agriculture on a much larger scale than those of the Swifterbant culture).
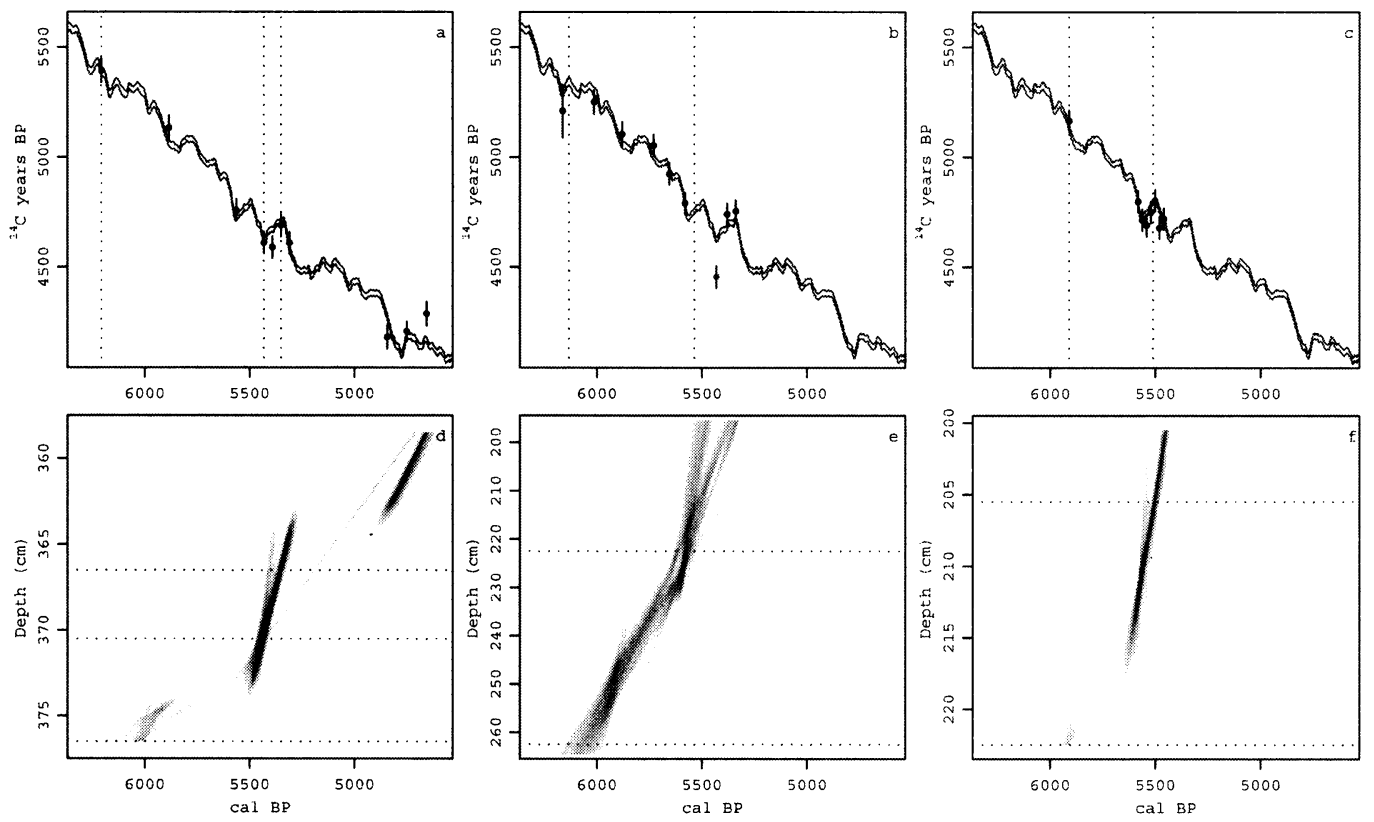

Figure 2 Bpeat age models from cores GietenV-A (a,d), GietenV-B (b,e) and GietenV-D (c,f). Panels a-c show the maximum a posteriori (MAP) fit (Blaauw and Christen 2005) of the ${ }^{14} \mathrm{C}$ dates to the IntCal04 calibration curve (Reimer et al. 2004), while vertical dashed lines show the MAP fit for events of interest (NOP-1, NOP-1a, NOP-1b, NOP-2); panels d-f show the Bpeat age models in grayscale (see text). Dashed lines show depths with events of interest (NOP-1, NOP-1a, NOP1b, NOP-2). 

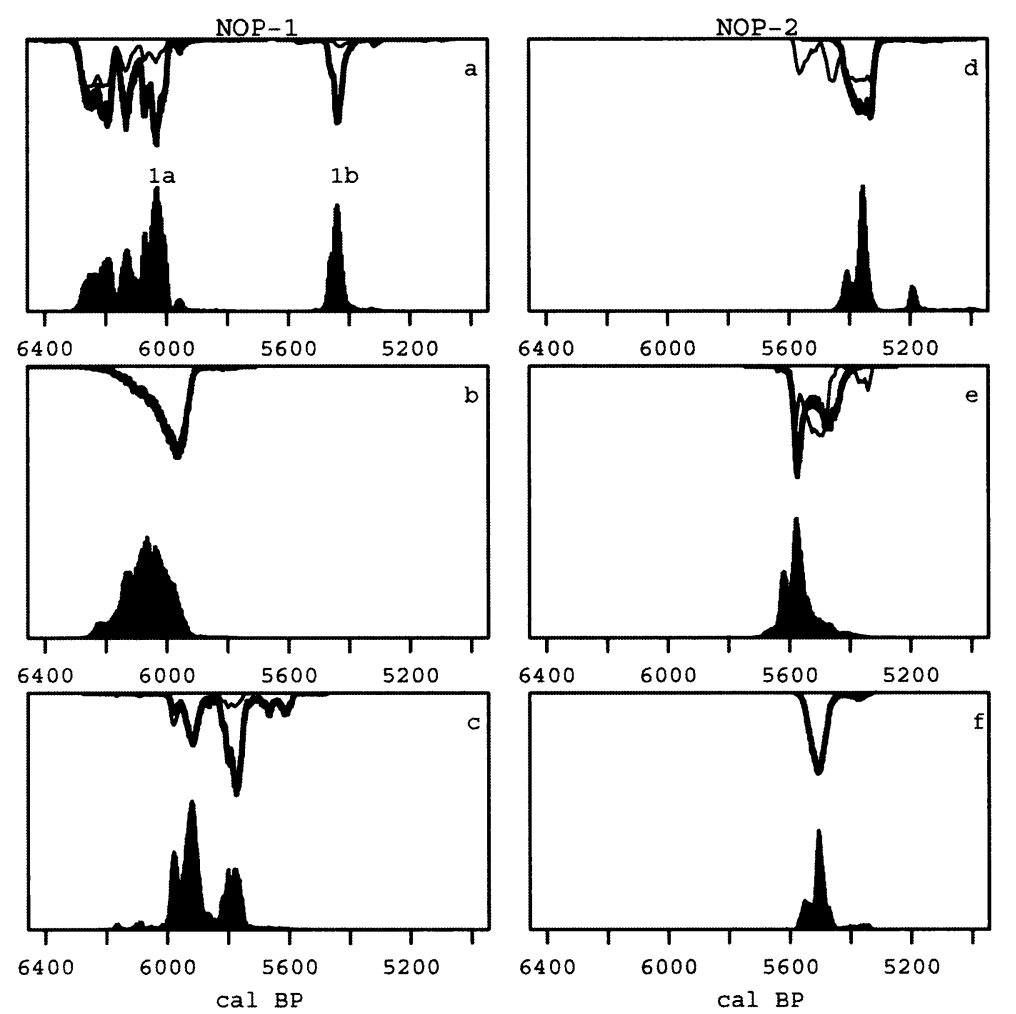

Figure 3 Calendar age distributions of archaeological events NOP-1 (a-c) and NOP-2 $(d-f)$ as inferred from cores GietenV-A (a,d), GietenV-B (b,e), and GietenV-D (c,f). NOP-1 is divided into $1 \mathrm{a}$ and $1 \mathrm{~b}$ in core GietenV-A, which is reflected in the bimodal distributions in (a). Filled black histograms are calendar ages inferred by Bpeat; hanging bold curves are those inferred from $\mathrm{BCal}$ assuming chronological ordering of the ${ }^{14} \mathrm{C}$ dates. Thin lines show calibrated ranges of individual dates when the exact NOP depths were ${ }^{14} \mathrm{C}$ dated; $y$ scales arbitrary.

\section{Hekla-3 Tephra in the Netherlands?}

Geochemically confirmed volcanic ash layers (tephra) are used widely for correlating cores between regions. The Hekla-3 tephra, which dates to around $3000 \mathrm{cal} \mathrm{BP}$, has been reported from its source area in Iceland (Boygle 1999), the North Atlantic Ocean (Eiríksson et al. 2000; Haflidason et al. 2000), Ireland (Plunkett 2006), Sweden (Zillén et al. 2002; Bergman et al. 2004; Boygle 2004; Wastegård 2005), and northern Germany (van den Bogaard et al. 2002), and has been ${ }^{14} \mathrm{C}$ dated to approximately 3100-2800 cal BP. Core Eng-XV from a raised bog peat deposit in the province of Overijssel (Netherlands) spans the mid to late Holocene and has been ${ }^{14} \mathrm{C}$ dated at very high resolution (57 dates on thoroughly cleaned aboveground macrofossils; Blaauw et al. 2004). As Hekla-3 tephra has not previously been reported from deposits in the Netherlands, and as core Eng-XV was ${ }^{14} \mathrm{C}$ dated at very high resolution, the core was inspected for tephra layers. At the Palaeoecology Center at Belfast University, 5-cm slices of core Eng-XV were analyzed microscopically for tephra (Pilcher and Hall 1992), after which slices with detected tephra were re-analyzed at the $\mathrm{cm}$ level. Only 1 level $(96 \mathrm{~cm}$ ) was found to contain some microscopic shards of tephra (data not shown), but tephra concentration was too low for geochemical analysis. Age models were constructed for this depth using Bpeat (prior settings: 2 sections; outliers 5\%; accumulation rate is most likely to be 
between about 10 and $30 \mathrm{yr} / \mathrm{cm}$ : AlphaMean $=20$, AlphaStd $=10$, epsilon $=5$; hiatus length could last up to centuries, HiatusA $=0.5$, HiatusB $=0.005$ ) and BCal (Buck et al. 1999). For BCal, all dated levels were assumed to be chronologically ordered, with the oldest dates at the bottom. The tephra layer (at $96 \mathrm{~cm}$ depth) was assumed to be younger than the ${ }^{14} \mathrm{C}$ dates at $97 \mathrm{~cm}$ and below, and to be older than the ${ }^{14} \mathrm{C}$ dates of $95 \mathrm{~cm}$ and up. The prior for the calendar age of the tephra layer was set as quasi non-informative (uniform distribution between 20,000 and $20 \mathrm{cal} \mathrm{BP}$ ). The Bpeat estimate for the calendar age of the tephra layer found in core Eng-XV is 3160-3090 cal BP (95\% ranges rounded to the nearest decades), while BCal estimates it to be 3220-3030 cal BP (Figure 4).

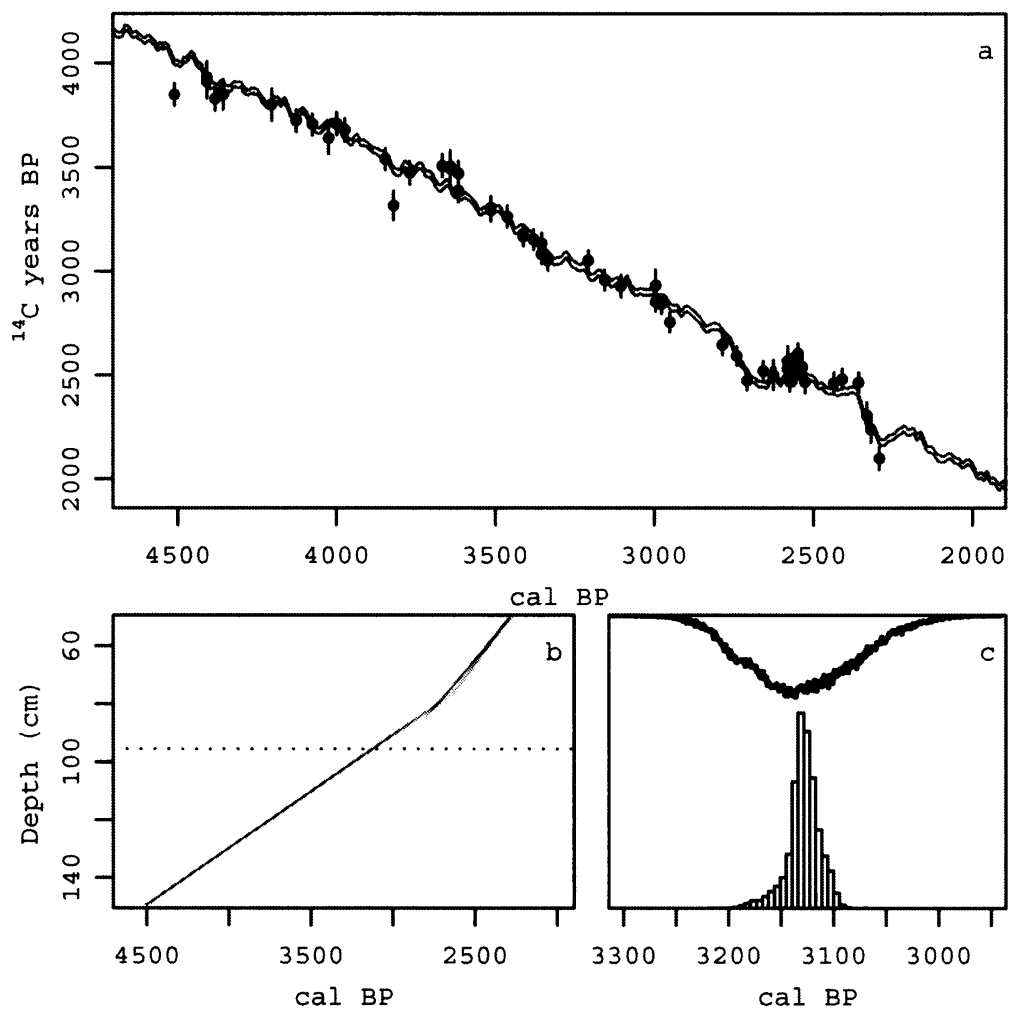

Figure 4 Bpeat age models from core Eng-XV. Panel (a) shows the maximum a posteriori (MAP) fit (Blaauw and Christen 2005) of the ${ }^{14} \mathrm{C}$ dates to the IntCal04 calibration curve (Reimer et al. 2004); b) shows the corresponding grayscale graph (see text); c) shows the posterior age distributions of the tephra layer at $95.5 \mathrm{~cm}$ depth. The Bpeat-inferred age is shown by the histogram, and the BCal-inferred age is shown by the "hanging" bold line; $y$ scale arbitrary.

\section{DISCUSSION}

Even though the Gieten $V$ cores were dated using wiggle-match dating of $8-10{ }^{14} \mathrm{C}$ dates, they could not provide highly precise age estimates for NOP- 1 . This is because i) the event was ${ }^{14} \mathrm{C}$ dated by only 1 or 2 levels isolated from the rest of the determinations in the sequences (non-overlapping calibrated distributions; cores GietenV-A and GietenV-D), or with only few dates before the event (core GietenV-B); and ii) plateaus and recurring ${ }^{14} \mathrm{C}$ ages are common in the calibration curve around this period, in effect causing confidence intervals of the "medium" resolution ${ }^{14} \mathrm{C}$ sequences to be nearly as large as those for individually calibrated ${ }^{14} \mathrm{C}$ dates. Event NOP-1b in core GietenV- 
A was covered by a denser sequence of ${ }^{14} \mathrm{C}$ dates, thus resulting in somewhat more precise age estimates for this event. Although NOP-2 was covered by several dates in all cores, the calibration curve varied much during this period (even higher density sequences would have been needed to properly match the dates to the calibration curve). Adding to this are the uncertainties in division levels of the multiple sections. Most resulting Bpeat confidence intervals are therefore not narrower than the calibrated ranges of the individual dates nearby the depths of interest (Table 1, Figure 3). We note that owing to modeling and data uncertainties, calendar age distributions are much more useful than point age estimates (e.g. MAP in Figure 2). The nature of the calibration curve during this period probably precludes precise $(<100 \mathrm{yr})$ age estimates from even high-resolution wigglematch dated ${ }^{14} \mathrm{C}$ sequences (see Figures 1-2 in Blaauw and Christen 2005).

The Gieten cores originate from a pingo scar (GietenV-A and GietenV-D consist of gyttja at the sections studied here, while GietenV-B consists of Sphagnum peat with occasional Eriophorum layers; Bakker 2003a). While the cores were wiggle-match dated under the model of piecewise linear accumulation, actually this model was constructed with raised bog peat deposits in mind (Blaauw and Christen 2005). Because the accumulation rate might well have fluctuated much more in pingo scars than in raised bog deposits, the Bpeat assumptions might not prove reliable here. However, the less stringent assumption of chronological ordering of dates using $\mathrm{BCal}$ did give results comparable to those of Bpeat (Figure 3). The hiatus inferred around $363.5 \mathrm{~cm}$ in core GietenV-A is not supported by stratigraphical or pollen evidence. However, without a hiatus the different sections would have needed much more varying accumulation rates (between about $6-250 \mathrm{yr} / \mathrm{cm}$ ), which is also difficult to rationalize.

The Bpeat estimate for the calendar age of the tephra layer found in core Eng-XV is $3160-3090 \mathrm{cal}$ $\mathrm{BP}(95 \%$ ranges rounded to the nearest decades), while $\mathrm{BCal}$ estimates it to be $3220-3030 \mathrm{cal} \mathrm{BP}$. A recently published calendar age estimate for the Hekla-3 layer is 3040-2960 cal BP, based on a wiggle-match of $12{ }^{14} \mathrm{C}$ dates from a northern German raised bog peat core (van den Bogaard et al. 2002). A Bpeat re-assessment of van den Bogaard's study results in an age of 3110-2950 cal BP (data not shown). Wastegård (2005) reports the age of Hekla-3 to be about 3100-2800 cal BP, while a more constrained estimate of 3040-2960 cal BP is given by Haflidason et al. (2000). Although the age estimate of the tephra layer in our core closely overlaps with most of these published estimates for Hekla-3, no geochemical identification of our tephra was possible, nor do Hekla-3 tephra shards have a unique color or morphology. Therefore, we cannot securely state that our tephra belongs to Hekla-3. However, while until now Holocene tephras had not yet been reported from Dutch peat deposits, our study indicates that microscopically-sized tephra can indeed be detected from these sites (see Pilcher and Hall 1992). Further work on finding the geographical distributions of tephras is therefore recommended.

Over the past years, Bpeat has been tested on dozens of ${ }^{14} \mathrm{C}$-dated cores from peatlands and other deposits. From this, we have learned that age modeling will probably never become entirely automatic and "objective"; every core has its peculiarities, which require decisions to be made by the researcher. However, most of these decisions can be implemented transparently, explicitly, and nonheuristically in a Bayesian framework such as Bpeat, BCal (Buck et al. 1999), or OxCal (Bronk Ramsey 2006). Below, we will discuss the most important issues, and consider planned enhancements of our framework.

An effective and often easily justifiable method to construct precise chronologies is to assume chronological ordering of dates, because the calibrated ranges of individual dates become constricted by the other dates in a sequence (at least when dating resolution is high enough for neighboring dates 
to have overlapping calibrated ranges). Chronological ordering can be selected in $\mathrm{BCal}$ and is a standard assumption in Bpeat (accumulation rates are forced to be positive and within ecologically plausible limits). However, the Bpeat assumption of linear accumulation constrains the calendar ranges of dated levels even more, as can be seen from Figures 3 and 4. Raised bog deposits accumulate in a surprisingly linear way (Belyea and Clymo 2001) and many high-resolution ${ }^{14} \mathrm{C}$-dated cores have been successfully matched under this assumption. However, assuming linear accumulation could be more dangerous with cores dated at lower resolution, as events of varying accumulation rate might be missed (Blockley et al., forthcoming). Even more, (piecewise) linear accumulation might be an overly constrictive assumption even for raised bog deposits (e.g. Yeloff et al. 2006). In order to allow for gradual changes in accumulation rate, authors JAC and MB are currently developing more flexible accumulation models for a future Bpeat version.

Besides gradual changes in accumulation rate, events such as local fires or altered vegetation composition could also cause abrupt accumulation rate changes. In Bpeat, these changes can be fixed to occur at predetermined levels (e.g. where stratigraphy strongly suggests such events), whereas the default is to infer these changes based on the fit of a ${ }^{14} \mathrm{C}$ sequence to the calibration curve. In the latter case, the locations of division levels (both on the depth and calendar scales) often show a considerable amount of uncertainty. The extensive light-gray areas around division levels (e.g. Figure 2, Blaauw and Christen 2005) show conclusively that many different age models can be fitted through a single set of ${ }^{14} \mathrm{C}$ dates.

Bpeat is currently set to allow for short- or long-lasting hiatuses at division levels. Hiatuses are common in raised bog peat deposits (e.g. Blaauw 2003; Blaauw et al. 2003) and Bpeat-inferred hiatuses are at times confirmed by stratigraphical indications (Blaauw and Christen 2005). However, some Bpeat users do not agree with having hiatuses in age models, especially when there is no supporting evidence for hiatuses in the stratigraphy. Therefore, a future version of Bpeat will contain an option to construct age models without hiatuses.

Outlier analysis is an important part of Bpeat, and as outliers occur regularly, outlier analysis should ideally be included in any approach to ${ }^{14} \mathrm{C}$ age modeling. In the cores studied here, we applied prior outlier probabilities of $5 \%$. The posterior outlier probabilities of the large majority of dates were $5 \%$ or lower, indicating that our outlier prior was possibly too pessimistic. Even though, 2 dates were identified as outliers: posterior outlier probabilities were about $88 \%$ for the date at $215.5 \mathrm{~cm}$ of core GietenV-B (Figure 2b), and $\sim 21 \%$ for the lowermost date of core Eng-XV (Figure 4). Other dates which appear offset, such as ${ }^{14} \mathrm{C}$ date of core Eng-XV floating below the other dates around $3800 \mathrm{cal}$ $\mathrm{BP}$, were not identified as likely outliers, probably owing to their larger measurement errors. Whereas the standard approach of Bpeat is to give similar prior outlier probabilities to all dates in a sequence (see above), this setting can be adapted. Several types of sequences show that outlying dates tend to be mostly younger (in case of peat deposits) or older (e.g. in lakes) than the other dates of the sequence. This could be explained by the processes of contamination, being mostly younger plant material in peat dates, and reworked older material in lake dates. We are planning to account for "directional outliers" in a future Bpeat version.

\section{ACKNOWLEDGMENTS}

MB was supported by SEMARNAT-CONACYT (SEMARNAT-2004-C01-7). MB and JAC thank the Bpeat Workshop participants (David Beilman, Keith Bennett, Eric Grimm, Dmitri Mauquoy, Gill Plunkett, Ron Reimer, Zicheng Yu) for their inspiring input. Andrew Millard and an anonymous reviewer are thanked for their help in improving this manuscript. 


\section{REFERENCES}

Bakker R. 2003a. The emergence of agriculture on the Drenthe Plateau-a palaeobotanical study supported by high-resolution ${ }^{14} \mathrm{C}$ dating $[\mathrm{PhD}$ dissertation]. Groningen University, the Netherlands. Archäologische Berichte 16. Bonn. 305 p.

Bakker R. 2003b. The process of Neolithization in the Pleistocene areas near the North Sea coast-evidence for early farming by the Swifterbant culture around $4000 \mathrm{cal}$ BC. Archäologische Informationen 26:33369.

Belyea LW, Clymo RS. 2001. Feedback control of the rate of peat formation. Proceedings of the Royal Society of London: Biological Sciences 268(1473):131521.

Bergman J, Wastegård S, Hammarlund D, Wohlfarth B, Roberts SJ. 2004. Holocene tephra horizons at Klocka Bog, west-central Sweden: aspects of reproducibility in subarctic peat deposits. Journal of Quaternary Science 19(3):241-9.

Blaauw M. 2003. An investigation of Holocene sun-climate relationships using numerical ${ }^{14} \mathrm{C}$ wiggle-match dating of peat deposits [ $\mathrm{PhD}$ dissertation]. University of Amsterdam, the Netherlands.

Blaauw M, Heuvelink GBM, Mauquoy D, van der Plicht J, van Geel B. 2003. A numerical approach to ${ }^{14} \mathrm{C}$ wiggle-match dating of organic deposits: best fits and confidence intervals. Quaternary Science Reviews 22(14):1485-500.

Blaauw M, van Geel B, Mauquoy D, van der Plicht J. 2004. Carbon-14 wiggle-match dating of peat deposits: advantages and limitations. Journal of Quaternary Science 19(2):177-81.

Blaauw M, Christen JA. 2005. Radiocarbon peat chronologies and environmental change. Applied Statistics 54(4):805-16.

Blaauw M, Christen JA, Guilderson TP, Reimer PJ, Brown TA. 2005. The problems of radiocarbon dating [Letters to the Editor]. Science 308(5728):1551-3.

Blockley SPE, Blaauw M, Bronk Ramsey C, van der Plicht J. Forthcoming. Building and testing age models for radiocarbon dates in Lateglacial and Early Holocene sediments. Quaternary Science Reviews.

Boygle J. 1999. Variability of tephra in lake and catchment sediments, Svínavatn, Iceland. Global and Planetary Change 21(1-3):129-49.

Boygle J. 2004. Towards a Holocene tephrochronology for Sweden: geochemistry and correlation with the North Atlantic tephra stratigraphy. Journal of Quaternary Science 19(2):103-9.

Bronk Ramsey C, van der Plicht J, Weninger B. 2001. "Wiggle matching" radiocarbon dates. Radiocarbon 43(2A):381-9.

Bronk Ramsey C. Forthcoming. Deposition models for chronological records. Quaternary Science Reviews.

Buck CJ, Christen JA, James GN. 1999. BCal: an on-line Bayesian radiocarbon calibration tool. Internet Archaeology 7. http://intarch.ac.uk/journal/issue7/ buck_toc.html.

Buck CJ, Higham TFG, Lowe DJ. 2003. Bayesian tools for tephrochronology. The Holocene 13(5):639-47.

Casparie WA, Groenman-van Waateringe W. 1980. Palynological analysis of Dutch barrows. Palaeohistoria 22:7-65.

Charman DJ, Garnett MH. 2005. Chronologies for recent peat deposits using wiggle-matched radiocarbon ages: problems with old carbon contamination. Radiocarbon 47(1):135-45.

Christen JA. 1994a. Bayesian interpretation of radiocarbon results [PhD dissertation]. University of Nottingham, United Kingdom.

Christen JA. 1994b. Summarizing a set of radiocarbon determinations: a robust approach. Applied Statistics 43(3):489-503.

Christen JA, Clymo RS, Litton CD. 1995. A Bayesian approach to the use of ${ }^{14} \mathrm{C}$ dates in the estimation of the age of peat. Radiocarbon 37(2):431-42.

Christen JA. 2003. Bwigg: an Internet facility for Bayesian radiocarbon wiggle-matching. Internet Archaeology 7. http://intarch.ac.uk/journal/issue 13/ christen_index.html.

Clymo RS, Oldfield F, Appleby PG, Pearson GW, Ratnesar P, Richardson N. 1990. The record of atmospheric deposition on a rainwater-dependent peatland. Philosophical Transactions of the Royal Society of London B 327:331-8.

Donders TH, Wagner F, van der Borg K, de Jong AFM, Visscher H. 2004. A novel approach for developing high-resolution sub-fossil peat chronologies with ${ }^{14} \mathrm{C}$ dating. Radiocarbon 46(1):455-63.

Eiríksson J, Knudsen KL, Haflidason H, Heinemeier J. 2000. Chronology of late Holocene climatic events in the northern North Atlantic based on AMS ${ }^{14} \mathrm{C}$ dates and tephra markers from the volcano Hekla, Iceland. Journal of Quaternary Science 15(6):573-80.

Friedrich WL, Kromer B, Friedrich M, Heinemeier J, Pfeiffer T, Talamo S. 2006. Santorini eruption radiocarbon dated to 1627-1600 B.C. Science 312(5773): 548.

Garnett MH, Stevenson AC. 2004. Testing the use of bomb radiocarbon to date the surface layers of blanket peat. Radiocarbon 46(2):841-51.

Guilderson TP, Reimer PJ, Brown TA. 2005. The boon and bane of radiocarbon dating. Science 307(5708): 362-4.

Gulliksen S, Birks HH, Possnert G, Mangerud J. 1998. A calendar age estimate of the Younger Dryas-Holocene boundary at Kråkenes, western Norway. The Holocene 8(3):249-59.

Haflidason H, Eiríksson J, van Kreveld S. 2000. The tephrochronology of Iceland and the North Atlantic region during the Middle and Late Quaternary: a review. Journal of Quaternary Science 15(1):3-22.

Hogg AG, Higham TFG, Lowe DJ, Palmer JG, Reimer PJ, Newnham RW. 2003. A wiggle-match date for 
Polynesian settlement of New Zealand. Antiquity 77(295):116-25.

Kilian MR, van der Plicht J, van Geel B. 1995. Dating raised bogs: new aspects of AMS ${ }^{14} \mathrm{C}$ wiggle matching, a reservoir effect and climatic change. Quaternary Science Reviews 14(1):959-66.

Kilian MR, van Geel B, van der Plicht J. 2000. ${ }^{14} \mathrm{C}$ AMS wiggle matching of raised bog deposits and models of peat accumulation. Quaternary Science Reviews 19(10):1011-33.

Kuzmin YV, Slusarenko IY, Hajdas I, Bonani G, Christen JA. 2004. The comparison of ${ }^{14} \mathrm{C}$ wiggle-matching results for the "floating" tree-ring chronology of the Ulandrik-4 burial ground (Altai Mountains, Siberia). Radiocarbon 46(2):943-8.

Mauquoy D, van Geel B, Blaauw M, van der Plicht J. 2002. Evidence from northwest European bogs shows 'Little Ice Age' climatic changes driven by variations in solar activity. The Holocene 12(1):1-6.

Mauquoy D, Blaauw M, van Geel B, Borromei A, Quattrocchio M, Chambers FM, Possnert G. 2004. Late Holocene climatic changes in Tierra del Fuego based on multiproxy analyses of peat deposits. Quaternary Research 61(2):148-58.

Norström E, Holmgren K, Mörth C-M. 2005. Rainfalldriven variations in $\delta^{13} \mathrm{C}$ composition and wood anatomy of Breonadia salicina trees from South Africa between AD 1375 and 1995. South African Journal of Science 101:162-8.

Oldfield F, Thompson R, Crooks PRJ, Gedye SJ, Hall VA, Harkness DD, Housley RA, McCormac FG, Newton AJ, Pilcher JR, Renberg I, Richardson N. 1997. Radiocarbon dating of a recent high-latitude peat profile: Stor Åmyrân, northern Sweden. The Holocene 7(3):283-90.

Pearson GW. 1986. Precise calendrical dating of known growth-period samples using a 'curve fitting' technique. Radiocarbon 28(2A):292-9.

Pilcher JR, Hall VA. 1992. Towards a tephrochronology for the Holocene of the north of Ireland. The Holocene 2(3):255-9.

Plunkett G. 2006. Tephra-linked peat humification records from Irish ombrotrophic bogs question nature of solar forcing at $850 \mathrm{cal}$ yr BC. Journal of Quaternary Science 21(1):9-16.

Raemaekers DCM. 1999. The articulation of a 'New Neolithic.' The meaning of the Swifterbant culture for the process of neolithisation in the western part of the North European Plain (4900-3400 BC) [PhD dissertation]. University of Leiden. Archaeological Studies Leiden University 3. Leiden.

Reimer PJ, Baillie MGL, Bard E, Bayliss A, Beck JW, Bertrand CJH, Blackwell PG, Buck CE, Burr GS, Cutler KB, Damon PE, Edwards RL, Fairbanks RG, Friedrich M, Guilderson TP, Hogg AG, Hughen KA, Kromer B, McCormac G, Manning S, Bronk Ramsey C, Reimer RW, Remmele S, Southon JR, Stuiver M, Talamo S, Taylor FW, van der Plicht J, Weyhenmeyer
CE. 2004. IntCal04 terrestrial radiocarbon age calibration, 0-26 cal kyr BP. Radiocarbon 46(3):1029-58.

Slusarenko IY, Christen JA, Orlova LA, Kuzmin YV, Buur GS. 2001. ${ }^{14} \mathrm{C}$ wiggle matching of the 'floating' tree-ring chronology from the Altai Mountains, southern Siberia: the Ulandryk-4 case study. Radiocarbon 43(2A):425-31.

Speranza A, van der Plicht J, van Geel B. 2000. Improving the time control of the Subboreal/Subatlantic transition in a Czech peat sequence by ${ }^{14} \mathrm{C}$ wiggle-matching. Quaternary Science Reviews 19(16):1589-604.

van de Plassche O, Edwards RJ, van der Borg K, de Jong AFM. 2002. ${ }^{14} \mathrm{C}$ wiggle-match dating in high-resolution sea-level research. Radiocarbon 43(2A):391402.

van de Plassche O, van der Schrier G, Weber SL, Gehrels WR, Wright AJ. 2003. Sea-level variability in the northwest Atlantic during the past 1500 years: a delayed response to solar forcing? Geophysical Research Letters 30(18):1921-4.

van den Bogaard C, Dörfler W, Glos R, Nadeau M-J, Grootes PM, Erlenkeuser H. 2002. Two tephra layers bracketing late Holocene paleoecological changes in northern Germany. Quaternary Research 57(3):314 24.

van Geel B, Mook WG. 1989. High-resolution ${ }^{14} \mathrm{C}$ dating of organic deposits using natural atmospheric ${ }^{14} \mathrm{C}$ variations. Radiocarbon 31(2):151-5.

van Zeist W. 1959. Studies on the post-Boreal vegetation of south-eastern Drenthe (Netherlands). Acta Botanica Neerlandica 8:156-85.

van Zeist W. 1967. Archaeology and palynology in the Netherlands. Review of Palaeobotany and Palynology 4:45-65.

Vorren K-D, Blaauw M, Wastegård S, van der Plicht J, Jensen C. 2007. High-resolution stratigraphy of the northernmost concentric raised bog in Europe: Sellevollmyra, Andøya, northern Norway. Boreas 36(3): 253-77.

Wastegård S. 2005. Late Quaternary tephrochronology of Sweden: a review. Quaternary International 130(1):49-62.

Wohlfarth B, Blaauw M, Davies SM, Andersson M, Wastegård S, Hormes A, Possnert G. 2006. Constraining the age of Lateglacial and early Holocene pollen zones and tephra horizons in southern Sweden with Bayesian probability methods. Journal of Quaternary Science 21(4):321-34.

Yeloff D, Bennett KD, Blaauw M, Mauquoy D, Sillasoo Ü, van der Plicht J, van Geel B. 2006. High precision ${ }^{14} \mathrm{C}$ dating of Holocene peat deposits: a comparison of Bayesian calibration and wiggle-matching approaches. Quaternary Geochronology 1:222-35.

Zillén LM, Wastegård S, Snowball IF. 2002. Calendar year ages of three mid-Holocene tephra layers identified in varved lake sediments in west central Sweden. Quaternary Science Reviews 21(14-15):1583-91. 